\title{
Commitment of Top Management in Implementing Ontinuous Improvement of Product Strategy: An Approach of Fighting Counterfeits by Manufacturing Firms in Uasin Gishu County.
}

\author{
John NgugiMwaura ${ }^{1}$, Dr. Susan C. Nzioki ${ }^{2}$, Doreen Njeje ${ }^{3}$ \\ ${ }^{1}$ Kenya Methodist University, \\ ${ }^{2}$ School of business and Economics, Kenya Methodist University \\ ${ }^{3}$ School of business and Economics, Kenya Methodist University,
}

\begin{abstract}
The purpose of the study was to look into the commitment of top management in implementing continuous improvement of product strategy: an approach of fighting counterfeits by manufacturing firms in UasinGishu County. The study employed a cross sectional survey design. Target population for the study was 231 manufacturing firms' employees in top level management, accounts, production and sales. However a sample of 146 was selected and this represents $63.2 \%$ of the target population using Stratified sampling technique. The researcher used primary data. The primary data was collected by use of semi-structured questionnaires. Quantitative data was analyzed by use of descriptive statistics. The study concluded that there is goodwill by top management in implementing implying that top management are willing to support in implementations of implementation of continuous improvement of product strategy in fighting counterfeit. The management had put in place the elements of the program that create a culture of continuous improvement by recognizing that brand protection is a business risk that needs top management support and direction. The study concluded that their Firm assists enforcement officers doing inspection by giving information and data. This implies that firms are trying their best to reduce the impacts of counterfeiters and have gone extra of using their resource to get information and deliver to enforcement officers. The study recommended in order reducing the impacts of counterfeiter's top management should be supportive in implementation and giving out known information in counterfeiters to enforcement officers to be dealt with in order continuous improvement their production.
\end{abstract}

Keywords: Commitment, Top management, Product strategy, Counterfeits.

\section{Introduction}

Globally counterfeits are sold in all notions and trademarks; they can be available anywhere in the world and in all sectors of the global economy. The products are produced and sold in underground economies or in unregulated economies where they escape normal tax tariff. The changing technology has greatly contributed to the rise in counterfeit products; this has greatly resulted to influx of such products into the market. Copy right infringement is a critical problem in global sales and marketing and it takes different forms. The first one is unauthorized copying and production of a product. An associative counterfeit or imitation uses a product name that differs slightly from a well-known brand; it is close enough that consumers associate it with a genuine product (Ennew et al., 2007). The second one is piracy, the unauthorized production or reproduction of copy, written material or work. The infringement of intellectual property rights (IPR) is well described in the W.T.O agreement on trade related aspects of international property rights (TRIPS) which includes patents, designs, rights amongst other rights (WTO,2001). Resource Based Theory (RBV) of the firm is one of the theoretical frameworks of this study. The foci of RBV are competitive advantages generated by the firm from its unique set of resources (Wernerfelt, 2004; Barney, 2006, 2001; Peteraf, 2003).

Trade in counterfeit products is a flourishing business and a major problem in the global economy. It is a multibillion dollar business which is spreading widely fast among the low income earners. Research shows that the rampancy of this trade and the rapidness of its growth is fueled by a number of factors ranging from limited supply of genuine products, inability to identify the original products, high prices of the original products, poverty, corruption and ignorance of the populace (Staake, \&Fleisch, 2008). The recent total removal of import restrictions and controls, digital technology, globalization and trade liberalization policies has also been associated with increased counterfeit products in the market. The consumers of counterfeits are duped into believing that counterfeit products are retailed at prices a fraction of the original products. Counterfeit products result to genuine companies globally losing up US\$ 630 billion annually (E.A.C Policy on Anti Counterfeits and Anti- piracy, 2009).

Manufacturers spend colossal sums of money in advertising, in the bid to market their goods. An unfair trade practice through intrusion in one's hard earned market zones is the greatest impediment to a 
manufacturer's sale. This translates into reduced sales, reduced margins; this may lead to either scaling down operations or closing altogether of manufacturing firms. Government Agencies like Ant-counterfeit agency, Kenya intellectual property Institute (KIPI), Kenya Bureau of Standards (Kebs) and many others mandated to deal with counterfeit products have done commendable work in trying to fight this vice. Counterfeit trading practices encourage evasion of taxes and impacts negatively on the country's economy. The effect on economic growth greatly reduces job creation and purchasing power, resulting into widespread poverty because of reduced sales (Globerman, 2007). The WHO estimates that approximately 10 percent of the global pharmaceutical market consist of counterfeit drugs, however this estimate increases to 25 percent for developing countries, and may exceed 50 percent in certain countries (World Health Organization, 2005). Appearance of counterfeit medicines in international commerce was first mentioned as a problem at the WHO Conference of Experts on Rational Drug Use in Nairobi, Kenya in 2005 (WHO 2005).

Continuous product improvement is the set of on-going systems engineering and management activities used to select, tailor, implement, and assess the processes used to achieve an organization's business goals (Lyman, 2007). Continuous improvement is recognized as a component of modern quality management. The state-of-the-art in system development management has evolved over the last few decades from basic concepts, practices, techniques, and tools borrowed from other disciplines to a relatively sophisticated suite of training, guided experience, and performance evaluation using structured collections of proven best practices. Experience has shown repeatedly that careful planning, frequent, regular review by trained, qualified people, and meticulous control of product components as they are developed, while not automatically sufficient by themselves, are necessary to defining and fielding a complex product or system today. The technology product and service industry as a whole has attempted numerous times to define, document, and disseminate collections of sound practice and specifications of product quality. These have taken the form of standards, specifications, methods, tools, books, and training and certification programs, among others (Staake, 2008).

\section{Statement of the Problem}

The rate at which counterfeits products are flocking the black market is steadily increasing at a very alarming rate. The need to counter the vice in Kenya is gaining interest from various governmental, private sector and non-governmental organizations thus a matter of public concern.Some small amounts of counterfeited products have been seized after the media highlights about them or the owner of the infringed property right reported about the vice. Criminal Case number 2415 of 2010 in Eldoret law courts is a good example of prosecution after a complaint lounged to the department of Weights and Measures in Eldoret involving Nokia products. In addition, senior management may not recognize that brand protection is a business risk that needs top management support and direction. Some managers do not support product development by not allocating enough time, money, space and other behaviors that would continuously improve product. Management should expect that when the total business solution is implemented that the increased level of counterfeit awareness in the organization is likely to result in an increase in the number of risks identified.It is against this background that the study will look into the effect of commitment of top management in implementing continuous improvement of product strategy: an approach of fighting counterfeits by manufacturing firms in UasinGishu County.

\section{Literature Review}

Manufacturing firms are facing stiff challenges due to counterfeits that are flooding the markets and are made easily available to unsuspecting consumers by dubious traders. For example, to achieve efficiency and effectiveness, the pharmaceutical manufacturers have come up with counter measures to protect their innovations as lack of this will lead to loss of integrity for their brands as well as tremendous decrease in sales. It is important to treat the brand protection process as one that is circular, not linear. Elements of the program that need to be in place to create a culture of continuous improvement by the management will involve senior management recognizing that brand protection is a business risk that needs top management support and direction (Kinghord and Wilson 2013). Also creation of business process that have controls developed to alert the management of potential opportunities for counterfeiters.

Management should clearly identify process to report, investigate and eliminate counterfeit opportunities or counterfeit products. Using the fruits of investigations, top management should educate employee on the product counterfeit risks and improve business process. Also top management should be willing to create performance matrices related to brand protection that are used in the evaluation of employee performance for compensation considerations. The firms might not afford to pursue all the strategies therefore priority must be established by the firm depending on the intended purpose of the strategy. The strategy chosen must also be consistent with the firm's vision, mission and objectives (Johnson and Scholes, 2009). Top management is supposed to keep performance standards of the Firm and if there is any drop or abrupt increase without adequate explanation, then that change should be investigated. Measurement of performance is the 
cornerstone of business practice because it assists in evaluation of the achievement of fundamental business goals and sets the scope and direction of possible improvement actions. Measurement of performance is relative depending on the industry (Fakii, 2013).First, for effective performance measurement, a balanced presentation of both financial and non-financial measures is required since no single measure can provide a clear performance target or focus attention on critical areas of the business (Miller, 2008).

The term "measurement" gets its meaning in the concise expression of Kaplan and Norton (2006) "if you cannot measure, you cannot manage". Second, the customer performance measures are critical in determining organization performance as being customer-focused is one of the basic and critical value in any organization today. Specific measures reflecting factors such as timely delivery of goods and services, quality and cost should be mentioned in any company mission statement. According to Morrow, 2002, the basic factors of customer as a performance measure include, customer loyalty, gaining new customers, customer profitability, and market and customer shares in targeted scope. Thirdly, the internal operation measures are obtained by focusing on actions and work process addressing critical success factors in empowering shareholder and customer satisfaction (Keegan et al., 2009).

The most important factor in this case is the necessity of defining and evaluating an exact internal operation value chain in the phases of design and development, production and commercializing in order to create value for both customer and shareholder. The internal operation measures' of performance include, the duration spent presenting a new product to the market, number of new products, sales percentage of new products, rate of defect, duration of production, production time and just-in-time delivery. Finally, learning and growth measures which constitute the idea that achieving the targets related with finance, customer and internal operations greatly depends on the learning and growth capability of the organization. Learning and growth measures especially address the question of what type of route should be followed in order for internal operation methods to be improved. These measures are employee centered and focused on employee satisfaction, productivity and sustainability.

\subsection{Conceptual framework}

The research study conceptualizes the concept of the top management on continuous improvement of product strategy as an approach in fighting counterfeit by manufacturing firms in UasinGishu County as shown in figure 1
Independent variable
Intervening variable
Dependent variable

\begin{tabular}{|c|c|c|}
\hline $\begin{array}{l}\text { Support by Top } \\
\text { management } \\
>\text { Avail resources } \\
>\text { Adhere to vision } \\
\quad \text { and mission } \\
>\text { Ensure quality } \\
\text { control }\end{array}$ & $\begin{array}{l}\text { Litigations and } \\
\text { enforcement } \\
>\text { Inspections } \\
>\text { Seizures } \\
>\text { Prosecution } \\
>\text { Compensation }\end{array}$ & $\begin{array}{l}\text { Litigations and } \\
\text { enforcement } \\
\quad>\text { Inspections } \\
>\text { Seizures } \\
>\text { Prosecution } \\
>\text { Compensation }\end{array}$ \\
\hline
\end{tabular}

Figure 1 Conceptual Framework

Source (Author, 2017)

\section{Materials and Research Methodology}

According to Kothari, (2004), a research design is the arrangement of conditions for collection and analysis of data in a manner that aims to combine relevance to the research purpose with economy in procedure.The study adopted a cross-sectional survey design which was analytical in nature. It will employ both quantitative and qualitative approaches. Cross-sectional research studies are based on observations that take place in different groups in this case among the employees at deferent sections of a Firm. This design was selected because it is the most viable choice for this research.Target population defined as a group of people or other units that are the focus of study and to whom the result are intended to generalize, Stacie Taylor, (2008). The target population is 231 and the sample size was 146 respondents obtained by applying the following formula:

$$
\begin{gathered}
\frac{N}{1+N\left(e^{2}\right)}=n \\
\frac{231}{1+231\left(0.05^{2}\right)}=146 \\
\mathrm{n}=146 \text { respondents }
\end{gathered}
$$

The researcher employed stratified sampling procedure as a method of sampling because the population is large, Saunders and Thornhill (2003) as well as Convenience sampling. According to Saunders and Thornhill 
(2003), convenience sampling is chosen purely on the basis of availability. Respondents are selected because they are accessible and articulate. Data collection was done through questionnaires. A structured questionnaire was provided to managers, accountants and other employees.Data from the questionnaires was described and keyed into SPSS in order to generate frequency and percentages.Regression analysis was used to determine the relationship between the variables and to draw statistical inferences.

Regression analysis was based on the model below.

$Y=\beta_{0}+\beta_{1} \chi_{1}+\beta_{2} \chi_{2}+\beta_{3} \chi_{3}+\beta_{4} \chi_{4}+C$

Where

$\mathrm{y}=$ Implementation performance of IPSAS

$\beta_{1}, \beta_{2}, \beta_{3}, \beta_{4}=$ Coefficients of independent variables

$\chi_{1}=$ Legal Framework

$\chi_{2}=$ Top Management Support

$\chi_{3}=$ Financial capability

$\chi_{4}=$ Technological Advancement

$\mathrm{B}_{0}=$ Constant

$\mathrm{E}=$ error term

\section{Results and Discussions}

Effect of Top Level Management Supportin implementing continuous improvement of product strategy The study sought to establish the effects ofsupport by top management in implementing continuous improvement of product strategy in UasinGishu County. The findings were analyzed as shown in the table 1;

Table 1 Effects of support by top management in implementing continuous improvement of product strategy

\begin{tabular}{|c|c|c|c|c|c|c|c|c|c|}
\hline Statements & & SA & $\mathbf{A}$ & $\mathbf{U}$ & D & SD & Mean & \%Mean & Std Deviation \\
\hline \multirow{2}{*}{$\begin{array}{l}\text { There is goodwill by top } \\
\text { management in implementing. }\end{array}$} & $\mathrm{F}$ & 71 & 68 & 1 & 0 & 0 & 4.50 & 90 & 0.52 \\
\hline & $\%$ & 51 & 48 & 1 & 0 & 0 & & & \\
\hline \multirow{2}{*}{$\begin{array}{l}\text { The firm is ready to embrace } \\
\text { changes }\end{array}$} & $\mathrm{F}$ & 68 & 70 & 2 & 0 & 0 & 4.45 & 89 & 0.54 \\
\hline & $\%$ & 48 & 50 & 2 & 0 & 0 & & & \\
\hline \multirow{2}{*}{$\begin{array}{l}\text { Top management apply Total } \\
\text { Quality management (TQM) }\end{array}$} & $\mathrm{F}$ & 70 & 69 & 1 & 0 & 0 & 4.49 & 89.8 & 0.52 \\
\hline & $\%$ & 50 & 49 & 0.7 & 0 & 0 & & & \\
\hline \multirow{2}{*}{$\begin{array}{l}\text { Management align firm skills } \\
\text { with resources }\end{array}$} & $\mathrm{F}$ & 66 & 73 & 1 & 0 & 0 & 4.46 & 89.2 & 0.52 \\
\hline & $\%$ & 47 & 52 & 0.7 & 0 & 0 & & & \\
\hline
\end{tabular}

Sample size $(n=140)$ Response Rate of $95.9 \%$

Key: SA: Strongly Agree. A- Agree, U- Undecided, D- Disagree, SD- Strongly Disagree

Source (Author, 2017).

The study results revealed that $89 \%($ mean $=4.45)$ were of the view that the firm is ready to embrace changes, $90 \%$ (mean=4.50) were of the opinion that there is goodwill by top management in implementing, $89.8 \%$ (mean=4.49) were of the opinion that top management apply Total Quality management (TQM) techniques, and $89.2 \%$ (mean=4.46) were of the view that Management align firm skills with resources.

The study results revealed that majority of the respondents were of the opinion that there is goodwill by top management in implementing continuous improvement of product strategy. This implies that top management is willing to support in implementations of implementation of continuous improvement of product strategy in fighting counterfeit. The management had put in place the elements of the program that create a culture of continuous improvement by recognizing that brand protection is a business risk that needs top management support and direction. Also creation of business process that have controls developed to alert the management of potential opportunities for counterfeiters. Top Management has clearly identified process to investigate report and eliminate counterfeit opportunities or counterfeit products.

The study findings shows that compared to last 5 years, the level of counterfeit trade affecting the respondents organization have increased for many organization with least having opinion of that it has decreased. They get this information through personal experience. This study finding indicate that manufacturing firms are facing stiff challenges due to counterfeits that are flooding the markets and are made easily available to unsuspecting consumers by dubious traders. For example, to achieve efficiency and effectiveness, the pharmaceutical manufacturers have come up with counter measures to protect their innovations as lack of this will lead to loss of integrity for their brands as well as tremendous decrease in sales. It is important to treat the brand protection process as one that is circular, not linear. 


\subsection{Discussions}

The study findings agrees with study done by Kinghord and Wilson (2013) who stated that elements of the program that need to be in place to create a culture of continuous improvement by the management will involve senior management recognizing that brand protection is a business risk that needs top management support and direction. Also creation of business process that have controls developed to alert the management of potential opportunities for counterfeiters. Management should clearly identify process to report, investigate and eliminate counterfeit opportunities or counterfeit products. Using the fruits of investigations, top management should educate employee on the product counterfeit risks and improve business process. Also top management should be willing to create performance matrices related to brand protection that are used in the evaluation of employee performance for compensation considerations.

The study findings also agrees with study done by Fakii, (2013), reported that top management is supposed to keep performance standards of the Firm and if there is any drop or abrupt increase without adequate explanation, then that change should be investigated. Measurement of performance is the cornerstone of business practice because it assists in evaluation of the achievement of fundamental business goals and sets the scope and direction of possible improvement actions. Measurement of performance is relative depending on the industry.

\section{Conclusions}

The study concluded that there is goodwill by top management in implementing implying that top management are willing to support in implementations of implementation of continuous improvement of product strategy in fighting counterfeit. The management had put in place the elements of the program that create a culture of continuous improvement by recognizing that brand protection is a business risk that needs top management support and direction

\section{Recommendations}

The study recommended that in order to reduce counterfeiter's, top management should be supportive in implementation and giving out known information in counterfeiters to enforcement officers to be dealt with in order continuous improvement their production.

\section{References}

[1]. Kinghord and Wilson (2013) anti-counterfeit strategy for brand owners, Centre for Anti- counterfeiting and product protection, Michigan State University.

[2]. Kothari, C. P. (2004). Research Methodology Methods and Techniques (second Ed) New Delh: Gupter for New Age International (p) Ltd.

[3]. Lyman and porter (2007) Perspectives on behavior in organizations, McGraw hill publishers.

[4]. Saunders, M., Lewis, P., \&Thornhill, A. (2009).Research methods for businessstudents. Harlow: Financial Times Prentice Hall. Ebook.

[5]. Staake, \&Fleisch, (2008) Countering Counterfeit Trade: Illicit Market Insights' Zurich Switzerland, ATH Zurich, department of management publishers 